\title{
Research on the Prediction Method of Gompertz Model for High Subgrade Settlement
}

\author{
Xiangxing Kong ${ }^{(\bowtie)}$ \\ The First Highway Survey and Design Institute of China Communications \\ Construction Company Ltd., Xi'an, China \\ 103121153@qq.com
}

\begin{abstract}
According to the development law of high embankment settlement, the Gompertz curve model is established. Combined with specific engineering example, the Gompertz curve well reflects the change process of high embankment settlement, and the prediction result of the model with the measured settlement value is very accurate and reliable.
\end{abstract}

\section{Introduction}

The construction of expressway in the west, high filling and excavation of roadbed structure are generally occur [1, 2]. After completion construction of high fill embankment subgrade settlement often appear, even cause the destruction of pavement structure engineering accident [3]. In order to ensure the safety of the normal operation of highway, according to the law of development of high filling subgrade settlement observation data and combining site, Gompertz curve model is applied to predict the settlement of the roadbed.

\section{Mechanism of High Filling Subgrade Settlement}

In the early period of construction, just after loading soil is in elastic status. The soil pore water do not exhaust $[4,5]$. Due to the soil of instantaneous shear de-formation, with the increase of load the settlement has approximately linear increase. In the later period of construction, with increasing load, the load imposed in high embankment are also more and more big. The pore water in the foundation soil is gradually discharged, meanwhile excess pore water pressure gradually decreases. So compaction causes more de-formation, and soil in embankment will be in elastic-plastic state. With the continuous development of the plastic zone, settlement rate increases quickly, until the load no longer increases.

After construction, due to the pore water pressure close to disappear completely, the consolidation process is not complete, settlement will continue with the passage of time, but significantly decreased sedimentation rate. If the time of settlement is infinity, settlement will be at ultimate state, and settlement rate is zero, so the settlement at that time is really the final settlement. In fact, time generally is large enough, for the highway time takes for 15 years plus filling time. 


\section{The Forecast Model of Gompertz Curve}

At present, there are two categories in calculation method of settlement of embankment. First, according to the constitutive model of consolidation theory combined with various soil, it is settlement calculation of the application of numerical methods, such as visco-elastoplastic finite element model method [6, 7]. The method of the calculation of the finite element method is very high, generally only used to calculate the key end of large engineering. And some constitutive model and engineering practice has a large gap, and needs a large number of soil tests to determine the soil parameters, so it is difficult to use in the general engineering design. Second, based on the measured data it is calculated settlement prediction method of quantity and time relations, such as hyperbola and exponential curve method. This method is concise and practical, and can satisfy the engineering precision requirement. Method for forecasting subgrade settlement of this selection is one of the Gompertz model.

Gompertz method is proposed by statisticians and mathematicians B. Gompertz, and it is also a growth curve, which are widely used in economics, management and statistics. Gompertz forecasting model is a growth curve model, and can be used to express and describe the process of growth and development. The practice indicated prediction model can be used as a reliable, effective method to forecast the settlement prediction of roadbed.

\section{Calculation of Parameters}

The three parameters in the model can be obtained using the three estimation. First of all, make it into a modified exponential form, then the data is divided into three sections (if not divisible by 3 , can increase and decrease the individual data which is a multiple of 3), each containing a number of segments, i.e., seek and obtain.

$$
\begin{aligned}
y_{t} & =e^{\left(k+a b^{t}\right)} \\
y^{\prime} & =k+a b^{t} \\
y_{1} & =k+a b^{1} \\
y_{2} & =k+a b^{2} \\
y_{3} & =k+a b^{3} \\
y_{t} & =k+a b^{T} \\
\sum_{1} y_{t}=\sum_{t=1}^{n} y_{t}=n k & +a b\left(b^{0}+b^{1}+b^{2}+\cdots+b^{n-1}\right)
\end{aligned}
$$




$$
\begin{aligned}
& \sum_{2} y_{t}=\sum_{t=n+1}^{2 n} y_{t}=n k+a b^{n+1}\left(b^{0}+b^{1}+b^{2}+\cdots+b^{n-1}\right) \\
& \sum_{3} y_{t}=\sum_{t=2 n+1}^{3 n} y_{t}=n k+a b^{2 n+1}\left(b^{0}+b^{1}+b^{2}+\cdots+b^{n-1}\right) \\
& \left(b^{0}+b^{1}+b^{2}+\cdots+b^{n-1}\right)=\frac{b^{n}-1}{b-1} \\
& \sum_{1} y_{t}=n k+a b \frac{b^{n}-1}{b-1} \\
& \sum_{2} y_{t}=n k+a b^{n+1} \frac{b^{n}-1}{b-1} \\
& \sum_{3} y_{t}=n K+a b^{2 n+1} \frac{b^{n}-1}{b-1} \\
& b=\sqrt[n]{\frac{\sum_{3} y_{t}-\sum_{2} y_{t}}{\sum_{2} y_{t}-\sum_{1} y_{t}}} \\
& a=\frac{b-1}{\left(b^{n}-1\right)^{2} b}\left(\sum_{2} y_{t}-\sum_{1} y_{t}\right) \\
& k=\frac{1}{n}\left(\sum_{1} y_{t}-a b \frac{b^{n}-1}{b-1}\right) \\
& k=\frac{1}{n}\left[\frac{\sum_{1} y_{t} \sum_{3} y_{t}-\left(\sum_{2} y_{t}\right)^{2}}{\sum_{1} y_{t}+\sum_{3} y_{t}-2 \sum_{2} y_{t}}\right]
\end{aligned}
$$

By using the method of analogy, Gompertz prediction parameters can be calculated as below:

$$
\begin{gathered}
a=\frac{b-1}{\left(b^{n}-1\right)^{2} b}\left(\sum_{2} \ln y_{t}-\sum_{1} \ln y_{t}\right) \\
b=\sqrt[n]{\frac{\sum_{3} \ln y_{t}-\sum_{2} \ln y_{t}}{\sum_{2} \ln y_{t}-\sum_{1} \ln y_{t}}} \\
k=\frac{1}{n}\left[\frac{\sum_{1} \ln y_{t} \sum_{3} \ln y_{t}-\left(\sum_{2} \ln y_{t}\right)^{2}}{\sum_{1} \ln y_{t}+\sum_{3} \ln y_{t}-2 \sum_{2} \ln y_{t}}\right]
\end{gathered}
$$




\section{Engineering Examples}

Combined with the subgrade settlement observation data in Hunan province Changde-Zhangjiajie expressway, the K103+380, K123+560 are chosen as the case study. The high fill subgrade filler is typical, where is filled with low liquid limit clay and shale, an embankment height is about $13 \mathrm{~m}$ (Fig. 1).

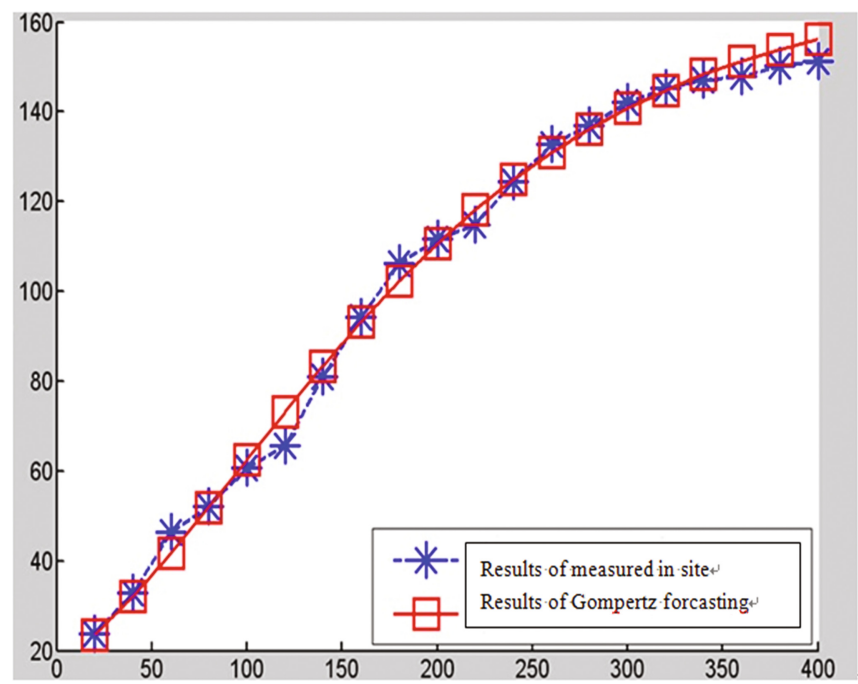

Fig. 1. Results of Gompertz and forecasting and measured in K123+560

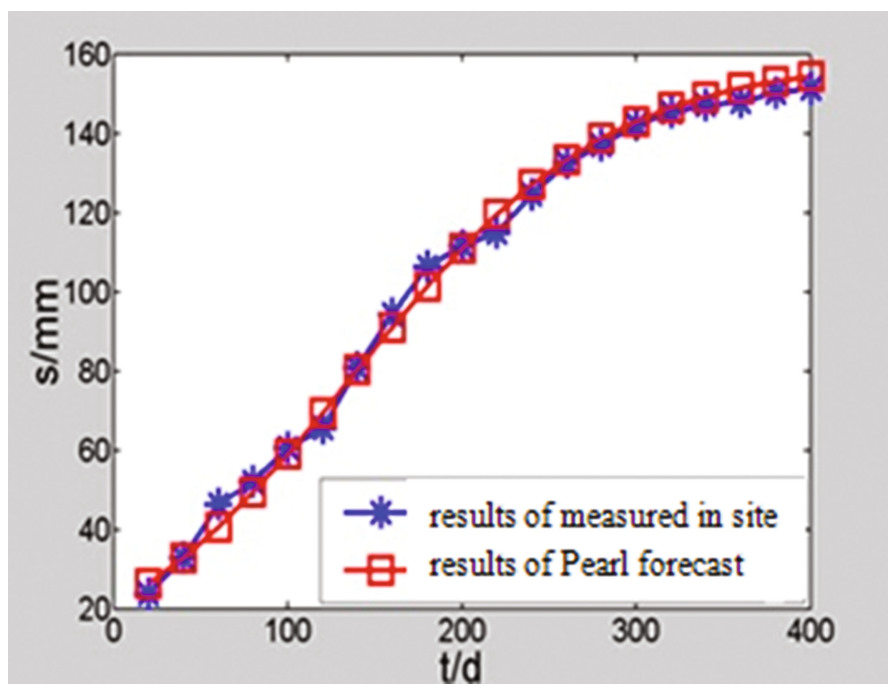

Fig. 2. Results of Pearl and forecasting and measured in K103+380 
In Fig. 2, the time-scattered settlement is "S" shape. The first 12 points (20-240 days) data are selected as samples, Matlab6.5 is used to calculate related parameters of Gompertz curve model (as shown in Table 1), then the results of Gompertz curve model for settlement prediction of roadbed (as shown in Table 2) are obtained, as well as the sum squared error (prediction precision) 168.13 (Table 3).

Table 1. Results of Gompertz and forecasting and measured in K123+560

\begin{tabular}{l|l|l|l}
\hline Time $(\mathrm{d})$ & Gompertz forecasting $(\mathrm{mm})$ & Measured in site $(\mathrm{mm})$ & Absolute error $(\mathrm{mm})$ \\
\hline 20 & 23.6187 & 23.9 & 0.3 \\
\hline 40 & 32.1777 & 32.9 & 0.7 \\
\hline 60 & 41.7554 & 46.3 & 4.6 \\
\hline 80 & 52.0064 & 52.1 & 0.1 \\
\hline 100 & 62.5736 & 60.6 & 2.0 \\
\hline 120 & 73.1273 & 65.7 & 7.5 \\
\hline 140 & 83.3896 & 80.9 & 2.5 \\
\hline 160 & 93.1464 & 94.4 & 1.3 \\
\hline 180 & 102.2482 & 106.3 & 4.1 \\
\hline 200 & 110.6040 & 111.6 & 1.0 \\
\hline 240 & 118.1724 & 114.9 & 3.2 \\
\hline 260 & 124.9498 & 124.6 & 0.3 \\
\hline 280 & 130.9612 & 132.7 & 1.7 \\
\hline 300 & 140.872502 & 137.0 & 0.7 \\
\hline 320 & 144.8878 & 142.3 & 1.4 \\
\hline 340 & 148.3601 & 145.2 & 0.3 \\
\hline 360 & 151.3503 & 147.1 & 1.3 \\
\hline 380 & 153.9166 & 148.0 & 3.3 \\
\hline 400 & 156.1125 & 150.2 & 3.7 \\
\hline & & 151.4 & 4.8 \\
\hline
\end{tabular}

Table 2. Results of Pearl and forecasting and measured in K103+380

\begin{tabular}{l|l|l|l}
\hline Time $(\mathrm{d})$ & Pearl forecasting $(\mathrm{mm})$ & Measured in site $(\mathrm{mm})$ & Absolute error $(\mathrm{mm})$ \\
\hline 20 & 25.32749 & 22.944 & 2.383488 \\
\hline 40 & 31.62893 & 31.584 & 0.044928 \\
\hline 60 & 39.0169 & 44.448 & 5.4311 \\
\hline 80 & 47.4527 & 50.016 & 2.5633 \\
\hline 100 & 56.79898 & 58.176 & 1.37702 \\
\hline 120 & 66.81466 & 63.072 & 3.742656 \\
\hline 160 & 77.17133 & 77.664 & 0.49267 \\
\hline \multicolumn{2}{|l|}{} \\
\hline
\end{tabular}


Table 2. (continued)

\begin{tabular}{l|l|l|l}
\hline Time $(\mathrm{d})$ & Pearl forecasting $(\mathrm{mm})$ & Measured in site $(\mathrm{mm})$ & Absolute error $(\mathrm{mm})$ \\
\hline 180 & 97.40851 & 102.048 & 4.63949 \\
\hline 200 & 106.6032 & 107.136 & 0.5328 \\
\hline 220 & 114.8543 & 110.304 & 4.550304 \\
\hline 240 & 122.0436 & 119.616 & 2.427648 \\
\hline 260 & 128.1486 & 127.392 & 0.756576 \\
\hline 280 & 133.2204 & 131.52 & 1.700352 \\
\hline 300 & 137.3577 & 136.608 & 0.749664 \\
\hline 320 & 140.6829 & 139.392 & 1.290912 \\
\hline 340 & 143.3236 & 141.216 & 2.107584 \\
\hline 380 & 145.4007 & 142.08 & 3.320736 \\
\hline 400 & 147.0224 & 144.192 & 2.830368 \\
\hline & 148.281 & 145.344 & 2.937024 \\
\hline
\end{tabular}

Table 3. Parameters of Gompertz method

\begin{tabular}{l|l|l}
\hline $\mathrm{K}$ & $\mathrm{a}$ & $\mathrm{b}$ \\
\hline 5.1264 & -2.3314 & 0.8426 \\
\hline
\end{tabular}

\section{Conclusion}

In the forecasting of road foundation settlement, different methods can often provide valuable information.

(1) The settlement of high embankment has its own law of development, Gompertz model can express $\mathrm{S}$ shape relationship between settlement and time of the whole process of subgrade. The settlement reflects very good, but also can be accurately applied in prediction of high embankment.

(2) Using the Gompertz model to forecast the settlement of roadbed, in order to obtain good prediction effect enough measured data is basis. The measured settlement value should be checked, and delete obvious error.

(3) In order to improve the prediction accuracy, the selection of measured sample points should be increased, and with the passage of time, the settlement of recent is added as the original sample, so that the prediction effect is better.

\section{References}

1. Highway Traffic Division: The Highway Engineering Quality Problems Prevent Guide. China Communications Press, Beijing (2002)

2. Xu, J., Cheng, K.K.: Road Engineering. Tongji University Press, Shanghai (1995) 
3. Zai, J.M., Mei, K.: Settlement of the whole process of prediction method. Rock Soil Mech. 21(4), 322-325 (2000)

4. Gu, X., Qian, H.J., et al.: The Foundation and Foundation. China Architecture Industry Press, Beijing (1993)

5. Pi, D.Y., Sun, Y.: Control and decision of multi model adaptive control. J. Algorithm 11(1), 77-80 (1996)

6. Zhao, M., Liu, Y., et al.: The soft soil roadbed settlement development law and its forecasting. J. Cent. South Univ. 35(1), 157-161 (2004)

7. Bates, J.M., Granger, C.W.J.: The combination of forecasts. J. Oper. Res. Soc. 20(4), 451-468 (1969). doi:10.2307/3008764. http://www.jstor.org/stable/3008764 